\title{
$600 \mathrm{~m}$ 以上超高层建筑抗震研究的新进展
}

我国是世界上地震灾害最为严重的国家, 全国 2/3 以 上的地方为地震区，20世纪中国因地震造成的死亡人数约 占全世界死亡人数总和的 $50 \%$. 与此同时, 随着我国经济 建设的迅速腾飞, 目前我国已是世界上超高层建筑最多的 国家，全世界 $300 \mathrm{~m}$ 以上的超高层建筑中，近 40\%位于我 国(含香港、台湾地区). 作为地标性的超高层建筑, 内部人 员众多、造价高昂，其抗震安全问题必须得到可靠保障. 超 高层建筑抗震问题得到了广泛关注和大量研究, 其中运用 先进的力学模型和分析方法, 准确预测超高层建筑在地震 下可能的倒塌模式和薄弱部位, 是保障和提高超高层建筑 抗震安全的重要科学依据和技术手段.

由清华大学卢啸、陆新征、张万开、叶列平等合作撰 写的“特大地震下超高层建筑的倒塌模拟”一文，通过开发 合理的数值模型, 完成了目前我国最高的建筑一上海 中心在特大地震下倒塌的全过程模拟和力学机理分析. 该 文即将发表于《中国科学: 技术科学》2011 年 41 卷第 11 期.

超高层建筑体量巨大、结构受力复杂, 其地震倒塌模
拟需要解决复杂构件建模和复杂受力分析, 倒塌过程构件 失效判据和断裂模拟，超大规模强非线性计算等一系列关 键问题. 该文作者提出基于有限元方法, 采用直接基于材 料本构模型的纤维梁单元和分层壳单元, 实现了超高层结 构中复杂构件的建模和受力分析; 采用单元失效算法和接 触算法，实现了倒塌过程中构件强非线性行为的模拟; 最 终完成了上海中心在特大地震下倒塌全过程的模拟, 预测 了结构的倒塌模式和破坏机理, 找出了结构潜在的薄弱部 位(图 1), 为研究和改进超高层建筑的抗震设计、保证其抗 震安全提供了重要依据.

该研究的创新之处在于，在国际上首次实现了 $600 \mathrm{~m}$ 以上的超高层建筑在特大地震下的倒塌全过程模拟, 为保 障超高层建筑抗震设计的安全性提供了重要参考. 研究所 开发的分析模型和分析方法, 不仅可以用于超高层建筑, 还可以用于一般建筑物、大跨建筑和桥梁结构的地震倒塌 模拟和抗震安全研究, 为未来大型土木工程抗震防灾研究 提供了重要的技术方法. 该课题得到国家自然科学基金重 大研究计划“重大工程的动力灾变”重点基金项目的支持.
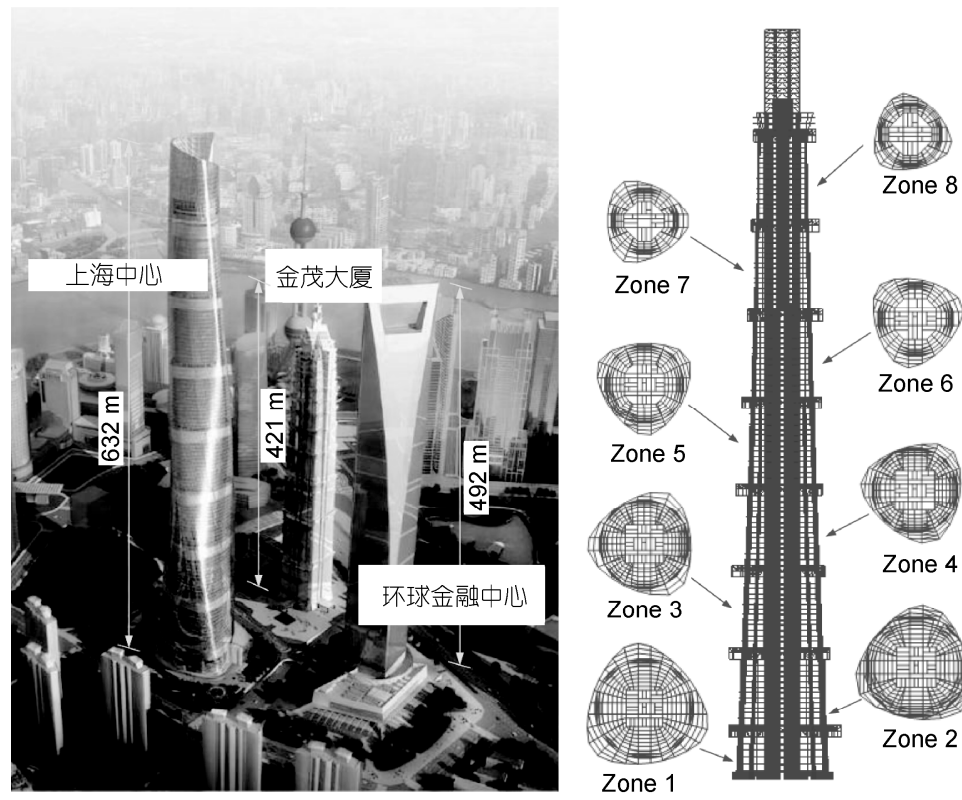

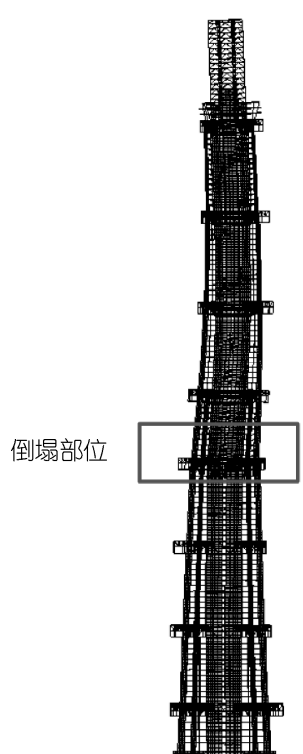

图 1 上海中心的外型、结构和可能的倒塌模式 